\title{
The Link Between Purchase Delay and Resale Price Maintenance: Using The Real Options Approach
}

\author{
Chen, Guan-Ru (Corresponding Author) \\ Department of Finance, I-Shou University \\ No.1, Syuecheng Rd., Dashu Township, Kaohsiung County, Taiwan \\ Tel: 886-952-067-759 E-mail: dionysiac@isu.edu.tw \\ Chen, Miao-Ling \\ Department of Finance, National Sun Yat-sen University \\ No.70, Lien-Hai Road, Kaohsiung, Taiwan \\ Tel: 886-525-2000 E-mail: miaolin@nsysu.edu.tw
}

\begin{abstract}
Why would a manufacturer want to impose resale price maintenance (RPM)? The traditional explanation of RPM is that it prevents retailers from free riding in providing services. In this paper, we show that the manufacturers still have incentives to impose RPM even their products do not need special services. When making a purchase decision, consumers choose from various alternatives, including options to delay the purchase, especially if they feel the price will be lower in the future. This paper connects frequent markdowns, purchase delay, and resale price maintenance (RPM) by using the real options analysis. The results indicate that the demand quantity under flexible pricing is lower than that under RPM, due to purchase delay. The profits of manufacturer will be lower without the use of RPM. This research also suggests that the manufacturer has more incentives to impose RPM on products with higher demand price elasticity. The results from real options analysis suggests that what we call consumers' purchase delay, which is caused by retailers' frequent markdowns makes RPM a desirable strategy for manufacturers.
\end{abstract}

Keywords: Resale price maintenance; Purchase delay; Real options approach

\section{Introduction}

Do retailers' frequent markdowns suppress or stimulate resale price maintenance (RPM)? This is an important issue in the current competitive environment characterized by substantial increases in intrabrand price competition and the use of RPM. Intrabrand price competition will lead to frequent markdowns among retailers. However, as a result of frequent markdowns, current demand may suffer if consumers are led to expect future prices to be lower. For example, it is widely thought that consumers delay automobile purchases in anticipation of future markdowns. When making a purchase decision, consumers choose from various alternatives, including the option of delaying the purchase. Consumers will delay their purchase if they feel the price will be lower in the future.

The key advantage and value of real options analysis is to integrate managerial flexibility into the valuation process. Real options analysis provides guidance that future decision possibilities and contingencies can affect manufacturers' decision significantly. This paper proposes the hypothesis that the uncertainty over retail price has negative effects on consumers' purchase decisions, which prompt the manufacturers to adopt appropriate marketing strategies. The relationship between frequent markdowns and RPM can be presented clearly under the real options framework. The standard "consumer free riding on special service theory" indicates that the motivation for manufacturers to impose RPM is to induce retailers to provide special services. However, as Klein and Murphy (1988, pp.265-266) and Mathewson and Winter (1998, p.68) note, RPM has been used for a much wider variety of products than the standard special-service theory would predict. The real options approach allows us to show that, even without the special service, the manufacturers still have strong incentives to impose RPM to reduce consumers' purchase delay.

This paper connects frequent markdowns, purchase delay, and resale price maintenance (RPM) by using the real options approach, thereby showing that the motivation behind RPM is to reduce the negative externality of frequent markdowns on consumers' purchase delay. In addition, the manufacturer has more incentives to adopt RPM if its product has higher demand elasticity.

\section{Literature Review}

There are several explanations for manufacturers choose to impose resale price maintenance (RPM) on their downstream retailers. Telser (1960) explains that RPM can exclude free riders from providing services. Mathewson and Winter (1983) show that manufacturers can use RPM to ensure the appropriate density of outlets, and consequently eliminate the problems of free riding and double marginalization. Mathewson and Winter (1984) specifically focus on examining the relationship between RPM and the spillover effect of advertising. When the exposure of advertising from one outlet spills into another outlet, retailers in outside areas may also benefit. Under these conditions, a manufacturer can ensure appropriate downstream behavior by using RPM. 
Marvel and McCafferty (1984) stated that RPM will be adopted when a manufacturer wishes to purchase quality certification from reputable retailers. Deneckere et al. $(1996,1997)$ find that the use of RPM will be most attractive to manufacturers when demand uncertainty leads to the prospect of deep price-cutting in the event of slack demand. Their study uses Nintendo as an example, suggesting that Nintendo tried to protect retail prices in order to promote adequate inventory holding. Flath and Nariu (2000) state the desire of Nintendo to impose RPM may have been to preserve sales revenue in low-demand states. Implicit in their models is the assumption that demand uncertainty does not definitely encourage manufacturers to impose RPM. Using data from Japan, Chen (1997) shows that manufacturers are encouraged to impose RPM to stabilize retail prices. Chen (2004) demonstrates that RPM reduces intrabrand price competition by impacting the effects of advertising. Moreover, Chen and Chen $(2006,2007)$ apply options concepts into RPM from the manufacturers' perspective. Chen $(1999, \mathrm{p} .442)$ summarizes these arguments as follows: "Explicit or implicit in these arguments is the belief that resale price maintenance is used because from the point of view of the manufacturer, there would otherwise be too much price competition among retailers".

Intrabrand price competition will lead to frequent markdowns among retailers. However, as a result of frequent markdowns, current demand may suffer if consumers are led to expect future prices to be lower. For example, it is widely thought that consumers delay automobile purchases in anticipation of future markdowns. Assuncao and Meyer (1993) suggest that increasing expectations of a price reduction in the near future increase the likelihood of purchase delay. They argue that past prices affect expectations regarding future prices. They hypothesize that increasing expectations of a price reduction in the near future increase the likelihood of purchase delay. Kalyanaram and Winer (1995) reason that, over time, promotions erode purchase probabilities by lowering reference prices and thereby increasing price sensitivity. As a result, consumers might be more reluctant to pay regular prices or tolerate price increases. Such arguments are consistent with a lie-in-wait strategy, in which consumers are less likely to buy at high prices as they learn to buy when prices are especially low. Bell and Bucklin (1999) develop the model of category purchase incidence. In their model, increased promotional exposure on prior store visits increases the reference value for the product category on the current store visit. Consequently, the difference between the category value and the reference value diminishes, which results in a reduced likelihood of a category purchase incidence. Therefore, increased long-term exposure to promotions might lead to a lower category purchase incidence probability on subsequent purchase occasions. Mela et al. (1998) also show that frequent price promotions persuade consumers to "lie in wait" for a lower price in the future.

As mentioned above, intrabrand price competition will lead to frequent markdowns among retailers. However, as a result of frequent markdowns, current demand may suffer if consumers are led to expect future prices to be lower. For example, it is widely thought that consumers delay automobile purchases in anticipation of future markdowns. Jacobson and Obermiller (1990) note that when making a purchase decision, consumers choose from various alternatives, including the options of delaying the purchase. This would imply that frequent markdowns would lead to purchase delay. RPM is used because there would be too much price competition among retailers. Since intrabrand price competition leads to frequent markdowns, consumers' options become valuable, thus persuading them to delay a purchase since they expect that they can buy it at a lower retail price in the future. Under this circumstance, the demand curve shifts downward and manufacturers thus become the victim of intrabrand price competition. As a result, manufacturers will be encouraged to impose RPM, in order to stabilize retail prices and reduce the negative effect from purchase delay.

\section{Real Options Approach and Its Analysis}

In the discipline of finance, Black and Scholes (1973) and Merton (1973) showed how to value a financial option whose payoff is contingent on the value of the underlying asset. Brennan and Schwartz (1985) and McDonald and Siegel (1985) were the first to actually apply these insights to investment valuation, which is now known as real options analysis. In this article, this paper connects frequent markdowns, purchase delay, and RPM by using the real options approach under the frameworks of Dixit and Pindyck (1994), to show that the motivation behind RPM is to reduce the negative externality of frequent markdowns on consumers' purchase delay.

Retailers set the price to optimize for the products in the whole store. They have strong incentive to provide discounts on the product with high consumer salience in order to draw store traffic. The strategy is called "loss leading schemes", also called "variable price merchandising," constantly raise and lower the prices of different products, both up and down. This price movement on hundreds of products makes it more difficult for consumers to compare prices on the same products among stores, thus reducing the amount of information on the market. Thus retailers use "loss leading schemes" to deter new entrants and protect monopoly power. However, as retail price fluctuates, consumers may expect there will be a lower price in the future, and have incentives to wait for a longer time. Under this circumstance, the demand curve shifts downward, manufacturers are hurt by intrabrand price competition. Manufacturers will be encouraged to impose RPM, in order to stabilize retail prices and reduce the negative effects from purchase delay. From the consumers' perspective, the retail price fluctuates over time in a way that is at least in part random. Therefore we can view the process of retail price as a stochastic process.

Assume a manufacturer produce one product that the demand curve is:

$$
P^{*}=M U / m=a Q^{-1 / \varepsilon}
$$


where $P^{*}$ is the reservation price, which is the price just low enough to result in purchase. $M U$ denotes the marginal utility that consumers get from the product, $a$ is a positive constant, $Q$ denotes the quantity demanded, $\varepsilon>1$ denotes the price elasticity of demand, and $m$ denotes marginal utility of money. The manufacturer decides how many quantities $Q$ to produce. Once the quantity $Q$ is determined, the manufacturer charges $(1-\lambda) a Q^{-1 / \varepsilon}=(1-\lambda) P^{*}$ as wholesale price for every unit sold by retailers. The $\lambda a Q^{-1 / \varepsilon}=\lambda P^{*}$ is the margin of per unit that the retailers can earn if they set the price at $P^{*}$. The positive constant $\lambda$ is determined under the negotiation among the manufacturer and retailers.

The manufacturer can choose input like labor, denoted by $v$, to produce $Q$. Suppose the input price is a positive constant $c$, and production function of manufacturer is

$$
Q=v^{\theta}, \quad 0<\theta<1 .
$$

Then the profit function of the manufacturer can be written as:

$$
\pi=\max _{v}\left[(1-\lambda) P^{*} Q-c v \mid\right.
$$

The instantaneous profit maximization gives the input demand function:

$$
v=\left[\frac{c \varepsilon}{(\varepsilon-1)(1-\lambda) a \theta}\right]^{\frac{\theta}{\theta-1}} Q^{\frac{\theta}{\varepsilon(\theta-1)}}
$$

and the supply function for output:

$$
Q=\left[\frac{c \varepsilon}{(\varepsilon-1)(1-\lambda) a \theta}\right]^{\frac{\varepsilon \theta}{\varepsilon(\theta-1)-\theta}}
$$

However the retail price, which is denoted by $P$, is not certainly set at $P^{*}=a Q^{-1 / \varepsilon}$. As noted previously, retailers have incentives to use frequent price discounts to draw store traffic. The retail price that fluctuates over time can be described as a stochastic process. Without loss of generality, we assume the stochastic process of retail price, $P$, follows the geometric Brownian motion:

$$
d P=\sigma P d W
$$

where $d W$ is the increment of a Wiener process, $\sigma$ denotes the frequency of price discounts. In order to obtain $M U$, consumers need to pay retail price $P$.

Before purchasing, consumers have the option to delay purchase, which be denoted by $K(P)$, which gives consumers the right, not obligation, to choose when to pay $P$ and in return receive $M U$. Consumers will delay their purchases in expectation a lower price, unless $M U>P+K(P)$. We can determine a unique threshold $P^{*}$; and a similar concept is the "reservation price," which is the price just low enough to result in purchase (Jacobson and Obermiller 1990). In addition, $P<P^{*}$ means $M U>P+K(P)$, indicating that consumers will make the purchase immediately. Using the Bellman equation and Ito's Lemma, $K(P)$ must satisfy the partial equation:

$$
\frac{1}{2} K^{\prime \prime}(P) \sigma^{2} P^{2}-\rho K(P)=0
$$

where $\rho>0$ denotes the discount rate. Simple substitution shows that the equation has solutions in the form $K(P)=k P^{\beta}$, provided $\beta$ is a root of the fundamental quadratic equation:

$$
\frac{1}{2} \sigma^{2} \beta(\beta-1)-\rho=0
$$

The roots of (6) are

$$
\beta_{1}=\frac{1}{2}+\sqrt{\frac{1}{4}+\frac{2 \rho}{\sigma^{2}}}>1
$$

and 


$$
\beta_{2}=\frac{1}{2}-\sqrt{\frac{1}{4}+\frac{2 \rho}{\sigma^{2}}}<0
$$

Then the general solution to equation (5) can be written as

$$
K(P)=k_{1} P^{\beta_{1}}+k_{2} P^{\beta_{2}}
$$

When the retail price is far beyond the consumers' reservation price, the prospect of its falling to the purchase threshold is quite remote. Therefore the option should be almost worthless at this extreme. It makes sense to require $K(P) \rightarrow 0$, as $P \rightarrow \infty$. However, since $\beta_{1}>1$, that power of $P$ goes to infinity as $P \rightarrow \infty$. To ensure that $K(P)$ goes to zero as $P$ goes to infinity, we must set the coefficient of the positive power of $P$ equal to zero, thus $k_{1}=0$, leaving

$$
K(P)=k_{2} P^{\beta_{2}}
$$

In addition, $K(P)$ must satisfy the following boundary conditions:

$$
\begin{aligned}
& K\left(P^{*}\right)=a Q^{-1 / \varepsilon}-P^{*} \\
& K^{\prime}\left(P^{*}\right)=-1
\end{aligned}
$$

By substituting (7) into (8) and (9) and rearranging, the solution of purchase threshold is

$$
P^{*}=a Q^{-1 / \varepsilon} \frac{\beta_{2}}{\beta_{2}-1}
$$

where

$$
\begin{gathered}
k_{2}=-\left(a Q^{-1 / \varepsilon}\right)^{1-\beta_{2}} \beta_{2}{ }^{-\beta_{2}}\left(\beta_{2}-1\right)^{\beta_{2}-1} \\
\beta_{2}=\frac{1}{2}-\sqrt{\frac{1}{4}+\frac{2 \rho}{\sigma^{2}}}<0
\end{gathered}
$$

After imposing RPM, $\sigma$ approaches zero since intrabrand price competition has been stabilized, the options for purchase delay become valueless. The $\beta_{2} \rightarrow-\infty$ as $\sigma \rightarrow 0$, thus, $P^{*}$ in (10) becomes:

$$
P^{*}=a Q^{-1 / \varepsilon}
$$

The equation (13) is exactly the form of equation (1), which is presented in most microeconomics textbooks.

The $P^{*}$ in (10) is lower than that in (13), indicating that frequent markdowns lead to a negative consequence by lowering consumers' reference prices (Jacobson and Obermiller 1990). Rearranging (10) and (13), respectively, yields demand curves under flexible pricing and RPM:

$$
\begin{gathered}
Q_{F L}=\left(P \frac{\beta_{1}-1}{a \beta_{1}}\right)^{-\varepsilon} \\
Q_{R P M}=\left(P \frac{\delta}{a \rho}\right)^{-\varepsilon}
\end{gathered}
$$

Figure 1 shows the demand curves under RPM and flexible pricing separately. We denote that volatility of retail price under flexible pricing $(\sigma=0.2)$ is higher than that under RPM $(\sigma \rightarrow 0)$. The demand quantity under flexible pricing at retail price $P_{0}$ is lower than that under RPM $\left(Q_{0}<Q_{1}\right)$, due to purchase delay caused by frequent markdowns. After imposing RPM, the demand curve under flexible pricing shifts upward to the demand curve under RPM, consequently, the manufacture can make up the damage $\left(Q_{1}-Q_{0}\right)$ caused by purchase delay.

Given $\sigma>0$, the reservation price of consumers is equation (10), therefore the average revenue function faced by the manufacturer is:

$$
(1-\lambda) P^{*}=(1-\lambda) a Q^{-1 / \varepsilon}
$$

Substituting the equation (16) into the equation (2), we can have the profit flow when the variable input is chosen optimally: 


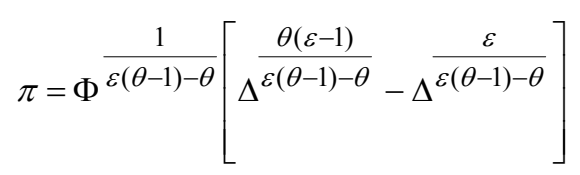

where

$$
\begin{aligned}
& \Phi=a^{-\varepsilon} c^{\theta(\varepsilon-1)} \\
& \Delta=\frac{\varepsilon\left(\beta_{2}-1\right)}{(\varepsilon-1) \beta_{2}(1-\lambda) \theta}
\end{aligned}
$$

We next examine how $\pi$ in (17) is affected by the change of intrabrand price competition. If the change of $\sigma$ leads to a lower $\pi$, meaning that this change encourages manufacturers to impose RPM. In Figure $2, \pi$ decreases as $\sigma$ becomes greater, representing the greater $\sigma$ encourages manufacturers to adopt RPM. The implication is: as frequent markdowns are increased by intrabrand price competition, consumers may delay their purchase because a lower retail price may appear in the future. The frequent markdowns raise the value of options to purchase delay, so manufacturers will have more incentives to impose RPM, which is designed to decrease the value of consumers' options. Facing the frequent price promotions, consumers' wait options encourage them to delay the purchase unless they need the products urgently. This is one of the reasons why the luxury goods and durable goods usually find it more necessary to use RPM than do necessary goods. For most consumers, the luxury goods and durable goods are different from daily necessities since they are not for daily or urgent uses. As a result, consumers could wait for a substantial price discount if there is no RPM.

In general, RPM is prohibited in most developed OECD countries. Opponents claim RPM is used for maintain cartel prices and reduce competition among retailers. This paper suggests that in the real options model, RPM may be used to inhibit the mobility of a price rather than to maintain a sufficiently high price. This study does not suggest that all RPM cases should be per se legal. Instead it provides a different perspective for studying RPM, and suggests the factors of purchase delay should be considered as courts examining the RPM cases.

The effect of the elasticity change on RPM also provides marketing implications for practitioners. We denote $B=|\partial \pi / \partial \sigma|$ as the benefit of imposing RPM, if the change of one parameter leads to greater $B$, it represents that this change favors RPM.

Figure 3 shows the relationship between demand elasticity $(\varepsilon)$ and the benefit of RPM $(B)$. If demand elasticity becomes higher, the manufacturer has more incentives to adopt RPM. Because facing the same markdown frequency, price-sensitive consumers are more motivated to delay their purchases in expectation of greater discounts. Consumers have the options to purchase right now or to purchase at a later date. The consumers with less price-sensitive may choose not to wait further even they understand there is possibility that the retail price will be lower in the future. On the contrary, facing frequent price promotions, the price-sensitive consumers have more incentives to delay their purchase because they regard the price as an important factor in their purchase decisions. Thus, the manufacturers of the products with higher demand price elasticity will impose RPM to remedy the downward demand which is caused by frequent price promotions.

The results can be extended for the explanation on the link between RPM and advertising. RPM for advertised goods has already been widely implemented in Japan. Using data from Japan, Flath and Nariu (2000) state all the products for which RPM was specifically authorized in Japan are branded, advertised products. Chen (2004) found the manufacturers are encouraged to impose RPM on advertised goods in order to weaken the promotional pricing effect of advertising.

Advertising increases a brand's salience to consumers and increases the demand price elasticity (Albion, 1983). Consumers use well-known advertised brands as a benchmark to compare pricing among retailers. Retailers recognized this fact and discount these advertised brands to draw store traffic and achieve reputations for low prices. Although the lower margin caused by intrabrand price competition, the retailers still find it necessary to carry advertised brands because of the effect of advertised brands on store traffic. Individual stores alternate those promoted brands through daily and weekly specials. The arguments that RPM ensures the retailers have an acceptable margin and enable high levels of coverage obviously can not explain why RPM usually impose on the advertised products. Because the reason that the retailers are willing to carry advertised brands is advertised brands' ability to draw store traffic rather than the higher margin brought by RPM. With higher unit sales, an advertised brand can have a lower gross margin than an unadvertised brand and still maintain the same total contribution. Therefore, the main motivations behind RPM may not intend to maintain high levels of coverage. To answer this question, our model provides another explanation for the use of RPM on advertised good. As noted previously, advertising exposes more information to consumers, thus increasing the consumers' price elasticity. If RPM is absent, facing intrabrand price competition, consumers would delay their purchase due to rising price sensitivity caused by advertising. The manufacturer recognizes this fact, thus has more incentives to use RPM on advertised goods. The 
imposition of RPM is designed to eliminate the negative effects that come from frequent markdowns, and to strengthen the effect of advertising.

\section{Conclusions}

When making a purchase decision, consumers choose from various alternatives, including the options of delaying the purchase. Consumers will delay their purchase if they feel the price will be lower in the future. We connect frequent markdowns, purchase delay, and RPM by using the real options analysis under the frameworks of Dixit and Pindyck (1994). This shows that the motivation behind RPM is to reduce the negative externality of frequent markdowns on consumers' purchase delay.

The results indicate that the demand quantity under flexible pricing is lower than that under RPM, due to purchase delay. After imposing RPM, the demand curve under flexible pricing shifts upward to that under RPM, so the manufacture can make up for the damage caused by purchase delay. This paper suggests that the motivation behind RPM is to reduce the negative externality of frequent markdowns on consumers' purchase delay. This paper also indicates that the higher price elasticity gives the manufacturer more incentives to use RPM. Taken together, the findings of this study suggest that what we call the purchase delay, which is caused by frequent markdowns, makes RPM a desirable strategy for manufacturers of certain types of products.

\section{References}

Albion, M.S. (1983). Advertising's Hidden Effects: Manufacturers' Advertising and Retail Pricing. MA: Auburn House Publishing.

Assuncao, J. L. \& Meyer, R .J. (1993). The Rational Effect of Price Promotions on Sales and Consumption. Management Science, 39(5), 517-535.

Bell, D. R. \& Bucklin R. E. (1999). The Role of Internal Reference Points in the Category Purchase Decision. Journal of Consumer Research, 26(2), 128-143.

Black, F. \& Scholes, M. (1973). The Pricing of Options and Corporate Liabilities. Journal of Political Economy, 81(3), 637-659.

Brennan, M. J. \& Schwartz, E. S. (1985). Evaluating Natural Resource Investment. Journal of Business, 58(2), 135-157.

Chen, M. L. (1997). Vertical Restraint and Advertising Effects, Hakuto-Shobo Publishing Company, Tokyo.

Chen, M. L. (2004). The Effects of Advertising on Retail Price Competition under Vertical Restraint - A Japanese Case. Journal of Business Research, 57(3), 227-283.

Chen, G. R. \& Chen, M. L. (2006). Incentives for Resale Price Maintenance from a Risk Perspective: Using a Real Options Analysis. Quarterly Fair Trade, 14(1), 135-151.

Chen, M. L. \& Chen, G. R. (2007). The Effects of Advertising on Resale Price Maintenance. Applied Economics, 39(4), 453-459.

Chen, Y. (1999). Oligopoly Price Discrimination and Resale Price Maintenance. Rand Journal of Economics, 30(3), 441-455.

Deneckere, R., Marvel, H.P. \& Peck, J. (1997). Demand Uncertainty and Price Maintenance: Markdowns as Destructive Competition. American Economic Review, 87(4), 619-641.

Dixit, A. \& Pindyck, R. S. (1994). Investment under Uncertainty. NJ: Princeton University Press.

Flath, D., \& Nariu, T. (2000), Demand Uncertainty and Resale Price Maintenance. Contemporary Economic Policy, 18(4), 397-403.

Ippolito, P. M. (1991). Resale Price Maintenance: Empirical Evidence from Litigation. Journal of Law and Economics, 34(2), 263-294

Jacobson, R. \& Obermiller, C. (1990). The Formation of Expected Future Price: A Reference Price for Forward-Looking Consumers. Journal of Consumer Research, 16(1), 420-432

Kalyanaram, G. \& Winer, R. S. (1995). Empirical Generalizations from Reference Price Research. Marketing Science, 10(1), 1-23.

Klein B. \& Murphy, K. M. (1988). Vertical Restraints As Contract Enforcement Mechanisms. Journal of Law and Economics, 31(2), 265-297.

Marvel, H. P. \& McCafferty, S. (1984). Resale Price Maintenance and Quality Certification, Rand Journal of Economics, 15(3), 346-359.

Mathewson, G. F. \& Winter, R. A. (1983). The Incentive for Resale Price Maintenance under Imperfect Information. Economic Inquiry, 21(3), 337-348.

Mathewson, G. F. \& Winter, R. A. (1984). An Economic Theory of Vertical Restraints. Rand Journal of Economics, 15(1), 27-38.

Mathewson, G. F. \& Winter, R. A. (1998). The Law and Economics of Resale Price Maintenance. Review of 
Industrial Organization, 13(1), 57-84.

McDonald, R. \& Siegel, D. R. (1985). Investment and the Valuation of Firms: When There Is an Option to Shut Down. International Economic Review, 26(2), 331-349.

Mela, C. F., Jedidi, K. \& Bowman, D. (1998). The Long-Term Impact of Promotions on Consumer Stockpiling Behavior. Journal of Marketing Research, 35(2), 250-262.

Merton, R. C. (1973). The Theory of Rational Option Pricing. Bell Journal of Economics and Management Science, 4(1), 141-183.

Telser, L. G. (1960). Why Should Manufacturers Want Fair Trade? Journal of Law and Economics, 3(1), 86-105.

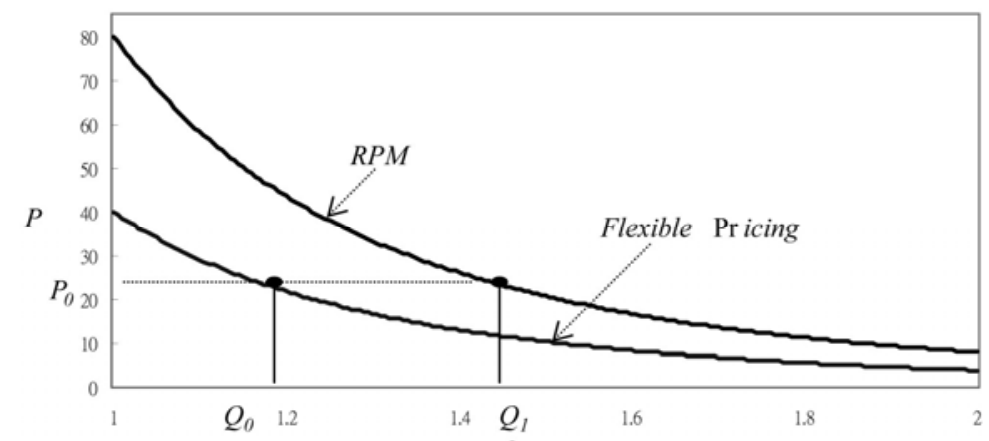

Figure1. Demand curves under RPM and flexible pricing

Parameter value: $\rho=0.04, \quad a=80, \varepsilon=0.3, \quad \sigma=0.2$

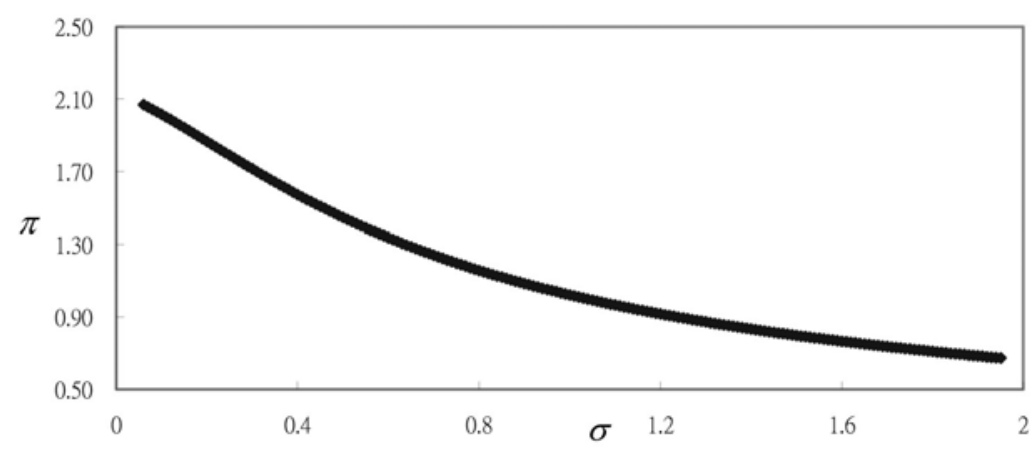

Figure2. The profit as a function of intrabrand price competition Parameter value: $\rho=0.04, \quad a=6, \quad c=12, \quad \theta=0.9, \quad \lambda=0.7$

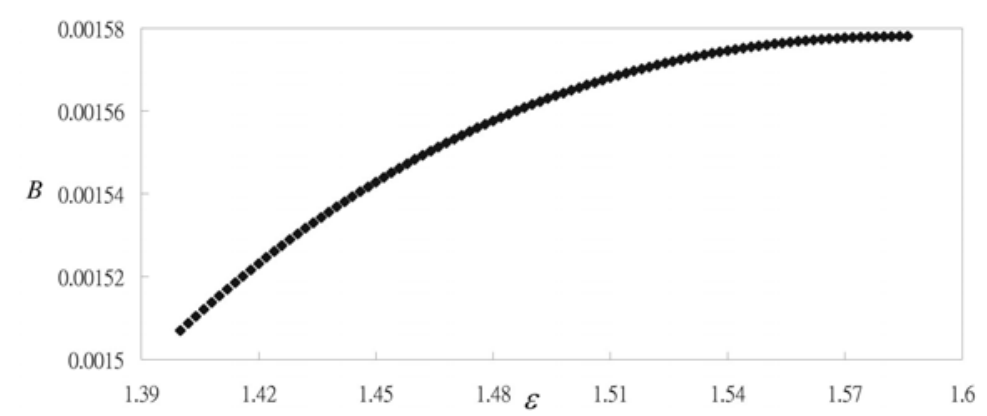

Figure3. The effect of an increase of demand elasticity on benefit of RPM Parameter value: $\rho=0.04, a=6, c=12, \theta=0.9 \quad \sigma=0.15, \lambda=0.7$ 